\title{
Ueber das Verhalten der Quecksilberoxydulsalze gegen Alkalien;
}

ron

C. Barfoed.

(Schluss.)

II.

\section{Verhalten der Quecksilberoxydulsalze gegen Ammoniak.')}

Obgleich mehrere werthvolle Untersuchungen über die schwarzgrauen bis schwarzen Niederschlägre, welche die Quecksilberoxydulverbindungen durch Behandlung mit Ammoniak geben, vorliegen, so ist doch die Frage, ob diese Niederschläge solche Verbindungen sind oder enthalten, die sich vom Quecksilberoxydul ableiten, nicht genügend aufgeklärt worden. Einige derselben werden allgemein für bestimmte Verbindungen angesehen, und diesen hat man Formeln beigelegt, die nach der ganzen Menge des darin enthaltenen Quecksilbers berechnet sind; und gleichfalls wird gewöhnlich angenommen, dass auch diejenigen Niederschläge dieser Art, von denen man weiss, dass sie freies Quecksilber und Abkömmlinge des Quecksilberoxyds enthalten, gleichzeitig Verbindungen, die von dem Quecksilberoxydul abzuleiten sind, enthalten. Andererseits hat aber Lef ort ${ }^{2}$ ) schon vor mehr als 40 Jahren mitgetheilt, dass, soweit seine Erfahrung reicht, dieselben alle freies Quecksilber enthalten, da sie, ähnlich den Kaliniederschlägen, Gold zu amalgamiren vermögen. Mit Guibourt ${ }^{3}$ ) nahm er an, dass die Kaliniederschläge nur Gemische aus Quecksilber und Quecksilberoxyd sind, und ferner war er der Ansicht, dass der Unter-

1) Mitgetheilt in der Sitzung der Kgl. Dänischen Gesellschaft der Wissenschaften am 24. April 1885. Gedruckt in: „Oversigt over det Kgl. Danske Videnskabernes Selkabs Forhandlinger, Kjóbenhavn 1885." I. Abhandlung, s. dies. Journ. [2] 38, 441.

2) In einem Anhange zu seiner Abhandlung über einige Quecksilberoxydulsalze: Journ. de pbarm. et de chim., 8, 5 (1845).

s) Dass diese Annahme unrichtig ist, habe ich im ersten Abschnitte dieser Mittheilung nachgewiesen. 
schied zwischen der Einwirkung von Kali und Ammoniak auf die Oxydulsalze derselbe ist, als bei ihrer Einwirkung auf die Oxydsalze (... que l'ammoniaque ne diffère de la potasse et de la soude que par l'action propre, qu'elle exerce sur les bisels de mercure ... a. a. O. S. 17). So hat er die Anschaung aufgestellt, dass die Ammoniakniederschläge der Quecksilberoxydulsalze nur Gemische aus feinem Quecksilber und den Ammoniakniederschlägen der entsprechenden Oxydsalze sind, dass also z. B. der Niederschlag des Chlorürs ein Gemisch aus metallischem Quecksilber und "Weissem Präcipitat" (Mercuriammoniumchlorid) ist, währenddem er sonst nach Kane für eine, der empirischen Formel $\mathrm{Hg}_{2} \mathrm{H}_{2} \mathrm{NCl}$ entsprechende Verbindung (Mercuroammoniumchlorid) angesehen wird. Directe Beweise dafür, dass sie solche Gemische sind, giebt L efort nicht. Er stützt sich nur darauf, dass sie Gold amalgamiren, und dass sie beim Auswaschen mit Wasser oder beim B thandeln mit mehr Ammoniak ein der grösseren oder kleineren Widerstandsfähigkeit der angenommenen Oxydverbindungen entsprechendes Verhalten zeigen. Es kann deswegen auch nicht überraschen, dass man seinen Ansichten keine grosse Aufmerksamkeit geschenkt hat'), sondern fortwährend die Niederschläge für wirkliche Oxydulverbindungen oder Gemische. die solche enthalten, ansah.

Das Folgende wird jedoch zeigen, dass Lefort Recht hat, insofern die Niederschläge auf gewöhnliche Weise, nämlich durch Zusatz einer zur völligen Zersetzung der Quecksilbersalze genügenden Menge Ammoniak, dargestellt werden. Ich muss aber hinzufugen, dass bei unvollständiger Zersetzung des Quecksilbersalzes Niederschläge anderer Art entstehen können - dies ist z. B. bei dem Mercuronitrat sicher der Fall - und was diese Niederschläge betrifft, so hat Lefort nicht Recht (vergl. S. $206 \mathrm{Anm}$.).

In dieser Mittheilung werde ich allein diejenigen Niederschläge behandeln, welche auf erstere Weise, also durch über-

1) Beispielsweise kann angeführt werden, dass Berzelius, obgleich er in seinem Jahresbericht f. $1846, \$$. 186 einen ziemlich ausführlichen Auszug aus Lefort's Abhandlung über die ungemischten Quecksilberoxydulsalze giebt, alles das völlig unberücksichtigt lässt, was in dem Anhange dazu über die Ammoniakniederschläge gesagt ist. 
Quecksilberoxydulsalze gegen Natron u. Ammoniak. 203

schüssiges Ammoniak, erhalten werden. Bevor ich aber zur Besprechung der einzelnen Niederschläge übergehe, schicke ich einige Bemerkungen über dieselben im Allgemeinen voraus.

Zunächst sei in aller Kürze bemerkt, dass Lefort's Angabe, sie enthalten freies Quecksilber, richtig ist. Mit Rücksicht hierauf habe ich mehrere derselben, nämlich die aus den salpetersauren, schwefelsauren, oxalsauren und essigsauren Salzen, sowie aus dem Chlorür und Bromür erhaltenen, untersucht, und indem ich nach den früher (I. Abhandlung) beschriebenen Methoden arbeitete, fand ich, dass sie alle in ganz frischem Zustande ein Blech aus chemisch reinem Golde stark amalgamiren, und dass sie, unter einer Glocke neben einer Schale mit Goldchloridlösung angebracht, bei gewöhnlicher Temperatur Quecksilberdämpfe abgeben, welche das Goldchlorid reduciren.

Was ich aber eingehender besprechen muss, ist ein. anderes für die vorliegende Frage sehr wichtiges Verhalten, welches sie beim Liegen an der Luft, sowohl im Dunkeln wie im Lichte und sowohl bei gewöhnlicher Temperatur als bei $100^{\circ}$ zeigen. Sie verlieren nämlich dann die schwarze oder schwarzgraue Farbe, die sie in frisch gefälltem oder getrocknetem Zustande besitzen, und werden nach einiger Zeit grauweis, gelblichweiss bis ganz weiss. Diese Aenderung verläuft im Ganzen unter densellen Umständen, wie beim Natronniederschlage; ich bemerkte dieselbe auch zuerst bei einigen Flocken des aus dem Chlorür erhaltenen Niederschlages, die bei dessen Auswaschen durch Decantiren auf dem Glase sitzen geblieben waren, und die am nächsten Tage ganz weiss waren, obgleich alles Chlorammonium ausgewaschen war. Dieses stimmt, wie man sieht, nicht nur damit überein, dass die Niederschläge Gemische sind, die freies, also direct verdunstendes Quecksilber enthalten, sondern deutet auch darauf hin, dass sie solche Gemische, wie von Lefort angenommen, sind. Um hierüber Kenntniss zu erhalten, habe ich einige derselben, und besonders solche, von welchen ältere Analysen, womit ich meine Resultate vergleichen konnte, vorliegen, nach denselben Methoden, die bei dem Natronniederschlage benutzt wurden, untersucht. Ich schicke noch ein für alle Mal die Bemerkung voraus, dass, wo eine Wägung der Niederschläge stattfand, 
dieselben in nur ausgewaschenem Zustande auf gewogenen Glasplatten ausgestrichen, darauf über Schwefelsäure getrocknet wurden u. s. w. Nachdem sie der Luft ausgesetzt gewesen waren, bis sie weiss oder hell waren, wurden sie, insofern die Versuche bei gewöhulicher Temperatur stattfanden, wieder vor der Wägung über Schwefelsäure aufbewahrt $u$. s. w. In den einzelnen Versuchen wurden gewöhnlich einige Decigramm in Arbeit genommell. Mehr kann man wohl nicht anwenden, da die Versuche dann leicht weniger gut gelingen, indem bei Auftragen einer dickeren Schicht des Niederschlages auf die Glasplatte leicht dunkle Flecke, die von einer unvollständigen Aenderung herrühren, zurückbleiben. Dazu kommt noch, dass die Versuche dann sehr zeitraubend und langweilig werden, sie können auch ohnehin lange genug - mehrere Monate dauern, wenn sie bei gewöhnlicher Temperatur angestellt werden. Jene Quantität ist aber auch gross genug, denn die Gewichtsverluste, um die es sich hier handelt, betragen, wie es aus dem Folgenden hervorgehen wird, meistens über $40 \%$. Bei rein qualitativen Versuchen, wo man nicht, wie bei der Wägung, die Grösse der Glasplatten zu berücksichtigen braucht, kann man selbstverständlich viel mehr Stoff verwenden; wichtig ist es hierbei auch nur, dass der Niederschlag ganz dünn àusgebreitet wird.

\section{Der Ammoniakniederschlag des salpetersauren} Quecksilberoxyduls.

Für die nachfolgenden Versuche wurde dieser Niederschlag aus einer verdünnten, schwach sauren Lösung von salpetersaurem Quecksilberoxydul durch Zusatz von verdünnter Ammoniaklösung in äusserst schwachem Ueberschusse dargestellt. Nach dem Auswaschen wurde er mit Essigsäure geprüft, worin er sich bis auf einen ganz kleinen Rest metallischen Quecksilbers löstc. Seine Farbe war schwarzgrau.

Auf eine Glasplatte dünn ausgestrichen und bei Luftzutritt zum Trocknen u. s. w. hingelegt, nimmt ein solcher Niederschlag bei gewöhnlicher Temperatur im Laufe einiger Tage oder Wochen, je nachdem er eine dünnere oder dickere Schicht bildet, eino rein, beinahe blendend weisse Farbe an, 
Quecksilberoxydulsalze gegen Natron u. Ammoniak. 205

und auf ähnliche Weise in einem mit Ventil versehenem Raume des Dampfapparates bei $100^{\circ}$ untergebracht, wird er im Laufe einiger Stunden gleichfalls weiss, doch meist mit einem schwach gelblichen Schimmer, besonders da, wo er etwas dicker liegt.

Der weisse Rest, den der Niederschlag so hinterlässt, stimmt in seinen allgemeinen Eigenschaften mit den Verbin. dungen überein, welche aus dem salpetersauren Quecksilberoxyd durch Ammoniak erzeugt werden. Beim Erhitzen mit starker Kalilauge entwickelt er Ammoniak. In der Wärme löst er sich in Essigsäure unter Bildung von Quecksilberoxydsalzen, und dieses Verhältniss verdient besondere Aufmerksamkeit, da der ursprïngliche Niederschlag auch in dieser Säure löslich ist. Denn da die Quecksilheroxydsalze freies Quecksilber unter Bildung von Oxydulsalzen aufnehmen können, welches selbstrerständlich um so leichter geschieht, je feiner vertheilt das Quecksilber ist (vergl. meine Mittheilungen über den Natronniederschlag Bd.38, 441 ff.), so ist es klar, dass die Löslichkeit des ursprïnglichen schwarzen Niederschlages in Essigsäure, und die Thatsache, dass die hierdurch gebildete Lösung Quecksilberoxydul enthält, nicht als Beweis dafür angesehen werden kann, dass er keine bedeutende Menge freien Quecksilbers enthält, oder dafür, dass er ursprünglich Quecksilberoxydul in irgend einer Form enthielt. Dieses gilt auch für andere Niederschläge, welche aus dem Quecksilberoxydulnitrate und Ammoniak in anderen Mischungsverhältnissen entstehen.

Bei der Bestimmung des Gewichtverlustes, welchen der Niederscblag bei $100^{\circ}$ in einem dunklen, der Luft zugänglichen Raume erleidet, fand ich in drei Fällen resp. 43,0\%-43,4\% und $43,9 \%$, also durchschnittlich $43,4 \%$. Diese Zahl stimmt mit der berechneten überein, wenn man annimmt, dass die erhaltene weisse Verbindung dieselbe ist, welche durch Zusatz von Ammoniakin kaum erkennbarem Ueberschuss zu einer verdünnten, kalten und schwach sauren Lösung von salpetersaurem Quecksilberoxyd, also unter denselben Bedingungen, die beim Oxydulsalze zur Bildung des schwarzen Niederschlages führten, gefällt wird. Die Zusammensetzung dieses weissen Niederschlages entspricht nach Mitscherlich und $\mathrm{K}$ ane der Formel

$$
\mathrm{HgN}_{2} \mathrm{H}_{4} 2 \mathrm{HgON}_{2} \mathrm{O} \text {, }
$$


oder nach Carey Lea $3 \mathrm{HgO}_{2} ; \mathrm{N}_{2} \mathrm{H}_{6} ; \mathrm{N}_{2} \mathrm{O}_{5}$, indem dieser noch ein Mol. Wasser dann annimmt; aus $3 \mathrm{Hg}_{2} \mathrm{O}, \mathrm{N}_{2} \mathrm{O}_{6}$ gefällt, müsste er also mit $3 \mathrm{Hg}$ gemischt sein. ${ }^{1}$ )

Das Molekulargewicht dieses Niederschlages ist demnach 772 oder 790 ; wird dazu für das freie Quecksilber 600 gerechnet, dann erhalten wir für das Gemisch 1372, resp. 1390, und der Gewichtsverlust, den ein solches Gemisch beim Verdunsten des freien Quecksilbers erleiden muss, berechnet sich also auf $43,7 \%$, resp. $43,2 \%$, also genau was die Versuche ergeben haben. Bekanntlich können aber auch andere Produkte aus salpetersaurem Quecksilberoxyd mittelst Ammoniak erhalten werden und möglicher Weise könnte auch unter den gegebenen Bedingungen eine gewisse Menge derselben gebildet werden, aber auf die Menge des in dem erhaltenen Niederschlage enthaltenen freien Quecksilbers kann solches nur geringen Einfluss austiben. Ein Gemisch aus der Verbindung $\mathrm{HgN}_{2} \mathrm{H}_{4} 3 \mathrm{HgO} . \mathrm{N}_{2} \mathrm{O}_{5}$ und $4 \mathrm{Hg}$, welches durch Zersetzung von $4 \mathrm{Hg}_{2} \mathrm{O}, \mathrm{N}_{2} \mathrm{O}_{5}$ erhalten werden könnte, würde z. B. $89,4 \%$ Quecksilber enthalten, davon die Hälfte, $47,7 \%$, in freiem Zustande.

Dass der dunkle Ammoniakniederschlag nicht einer anderen Aenderung an der Luft bei $140^{\circ}$ als bei gewöhnlicher Temperatur, oder im Lichte als im Dunkeln unterliegt, und also ein Gemisch der angeführten Beschaffenheit sein muss, geht aus den folgenden Versuchen hervor, bei welchen er auf 4 Glas-

1) Man wird bemerken, dass dieses Mischungsverhältniss aueb der früher für „Hahnemann's Quecksilber" angenommenen Formel:

$$
3 \mathrm{Hg}_{2} \mathrm{O} \quad \mathrm{N}_{2} \mathrm{H}_{6} \cdot \mathrm{N}_{2} \mathrm{O}_{5}
$$

entspricht. Ich bespreche nicht dieses Präparat, da es durch unvollständige Fällung erhalten wird: und da ich nicht Gelegenheit gehabt habe, alle Produkte einer solchen zu untersuchen; ich theile aber doch mit, dass der schwarze Niederschlag, der von $\mathrm{K}$ ane erhalten wurde, indem er nur 1/4 des zur vollständigen Fällung nöthigen Ammoniaks zusetzte, und den er für eine Verbindung der Zusammensetzung:

$$
\mathrm{N}_{2} \mathrm{H}_{6} \cdot \mathrm{N}_{2} \mathrm{O}_{5}^{-} \cdot 2 \mathrm{Hg}_{2} \mathrm{O}
$$

und für den charakteristischen Bestandtheil in „Hahnemann's Quecksilber" hält (Ann. Chim. 72, 262), auch cin Gemisch ist, welches freies Quecksilber in ansehnlicher Menge enthält, aber bei langem Liegen an der Luft schwarz bleibt und also von dem soeben besprochenen Niederschlage, der durch Verdunsten des freien Quecksilbers weiss wird, wesentlich verschieden ist. 
platten vertheilt und der Einwirkung der Luft in der unten angeführten Weise, a-d, so lange ausgesetzt wurde, dass weder Farbe noch Gewicht sich weiter änderte.

a) Eine solche Platte wurde in einem finstern Raume unter Zutritt der Luft ungefähr 7 Stunden lang auf $100^{\circ}$ erwärmt. Der Niederschlag war dann weiss und hatte $43,4 \%$ an Gewicht verloren. Nach fortgesetztem 24stündigen Erbitzen war kein weiterer Gewichtsverlust zu bemerken.

b) Ein anderer Theil desselben Niederschlages wurde bei gewöhnlicher Temperatur in freier Luft und bei Tageslicht (nicht directem Sonnenlicht) hingelegt. Nach 8 Wochen war er weiss und hatte $42,6 \%$ an Gewicht verloren.

c. Eine Platte wurde bei gewöhnlicher Temperatur in einen dunklen Schrank, dessen Thür, um der Luft freien Zutritt zu lassen, hin und wieder über Nacht offen gelassen wurde, gebracht. Nach 10 Wochen war der Niederschlag weiss und der Verlusst betrug $43,3^{\circ} \%$.

d. Endlich wurde der Niederschlag auf der Glasplatte in ein mit Glasstöpsel versehenes 3-Liter-Glas gebracht. Dieses Glas wurde in denselben Schrank, der unter $c$ benützt wurde, also in's Dunkele, gestellt. Innerhalb 10 Wochen war weder eine Farbenänderung noch eine Abnahme des Gewichts zu bemerken, während in derselben Zeit der Niederschlag unter c weiss wurde. Das Glas wurde darauf ans dem Schranke in das Tageslicht (nicht Sonnenlicht), also unter denselben Bedingungen wie bei $b$, gebracht. Auch jetzt blieb der Niederschlag so dunkel wie früher, und nach 5 Wochen war noch keine Gewichtsabnahme zu constatiren. Darauf, also im Ganzen nach 15 Wochen, wurde soviel Goldchlorid in das Glas gebracht, dass der Boden desselben davon bedeckt war. Es dauerte jetzt nur ein paar Stunden bis die Reduction des Goldes anfing, und ein paar Tage, bis die Kanten des Niederschlages anfingen weiss zu werden; jetzt konnte nämlich das freie Quecksilber fortwährend ungehindert verdunsten, indem die gebildeten Quecksilberdämpfe von der Goldchloridlösung absorbirt wurden (vergl. Natronniederschlag Bd. 38, 462). Im Laufe von 1, 2 und 3 Monaten verlor denn auch der Niederschlag resp. $20 \%, 32 \%$ und $40 \%$ an Gewicht, und als er nach $31 / 2$ Monaten, mit Ausnabme einiger weniger, ziemlich 
scharf umschriebener grauer Flecken, wo er gewiss in zu dicker Schicht lag, ganz weiss geworden war, und auch bei weiterem Hinlegen nicht mehr an Gewicht verlor, betrug der Gewichtsverlust $40,5 \%$. Zum Vergleich wurde das reducirte Gold gesammelt und bestimmt; hieraus berechnet (vergl. Natronniederschlag Bd. 38, 467), hätte das Gewicht des verdunsteten Quecksilbers $40,38 \%$ betragen.

Das oben Angeführte zeigt, dass die schwarzgraue Farbe des Niederschlages, der durch Fällung von Mercuronitrat mit überschüssigem Ammoniak erbalten wird, nicht von irgend einer Verbindung des monovalenten Quecksilbers herrührt, sondern lediglich von freiem Quecksilber, und dass der zweite Bestandtheil desselben ganz weiss ist und sich dem Quecksilberoxyd anschliesst. Die Annahme, dass das Quecksilberoxydulsalz bei Fällung mit Ammoniak die Hälfte des darin enthaltenen Quecksilbers als freies Metall abgiebt, erscheint demnach vollständig berechtigt. Dafür spricht auch die Thatsache, dass dieser Niederschlag unter Umständen, wo keine chemische Aenderung desselben anzunehmen ist, über $40^{\circ} \%_{0}$ Quecksilber im freien Zustande abgiebt.

Ueber diese letzte Annahme, dass das Quecksilber sich während der Fällung in zwei gleiche Theile theilt, von denen der eine frei wird, der andere gebunden bleibt, muss jch noch ein paar Worte sagen, wie ich denn auch darauf zurückkommen werde, da verschiedene Einzelheiten noch einer näheren Erklärung bedürfen. - Es muss nämlich auffallen, dass der Gewichtsverlust gewöhnlich etwas unter der Hälfte des in dem Niederschlage vorhandenen Quecksilbers liegt, und da die hinterbleibende weisse Verbindung also etwas mehr als die Hälfte enthalten muss, könnte es den Anschein haben, als ob die Theilung nicht in zwei ganz gleiche Theile geschehe. Allerdings ist der Unterschied nur klein, aber ich muss doch beifügen, dass er gewöhulich doch etwas grösser. erscheint, wenn die Quecksilbermenge des ursprünglichen Niederschlages nicht wie hier mit dem Gewichtsverluste, sondern mit dem Quecksilbergehalte des weissen Restes verglichen wird. Als Beispiel mag hier angeführt werden, dass einer der erwähnten Niederschläge, der bei $100^{\circ} 57 \%$ des weissen Restes hinterliess, also $43^{\%} !_{0}$ an Gewicht verloren hatte, $88 \%$ 
Quechsilberoxydulsalze gegen Natron u. Ammoniak. 209

Quecksilber ${ }^{1}$ ) enthielt, der weisse Rest dagegen $81,7^{\circ} / 0^{.}$Von den 88 Gewichtstheilen Quecksilber waren demnach in dem Reste 46,6 vorhanden, also nur 41,4 verflüchtigt. Dieser Unterschied zwischen den Mengen des verdunsteten und des zurückgebliebenen Quecksilbers lässt sich aber trotz dessen mit der gemachten Annahme vereinigen, dass der frische Niederscllag ebenso viel freies wie gebundenes Quecksilber enthält. Der Unterschied kann nämlich erstens davon herrühren, dass der ursprüngliche Niederschlag, obgleich auf die Glasplatte dünn aufgestrichen, doch hier und da zu dick lag, um alles Quecksilber frei verdunsten zu lassen, oder davon, dass die hier so fein vertheilten Bestandtheile in der zwischen der Fällung und dem vollständigen Weisswerden verflossenen Zeit so auf einander eingewirkt haben, dass ein kleiner. Theil des freien Quecksilbers in gebundenen Zustand übergegangen ist, auf ähnliche Weise, wie wenn es sonst, sei es auf dem nassen Wege oder durch Wärme, mit den Oxydsalzen in Reaction tritt; denn dass solches in der That bei trockenen Gremischen der hier vorliegenden Art nicht nur bei $100^{\circ}$, sondern auch bei gewöhnlicher Temperatur stattfinden kann, wenn sie lange Zeit stehen, geht aus den unten S. 214 u. f. beschriebenen Versuchen hervor.

Der Ammoniakniederschlag des schwefelsuren Quecksilberoxyduls.

Zur Darstellung dieses Niederschlages habe ich frisch bereitetes und ausgewaschenes schwefelsaures Queeksilberoxydul, aus dem Nitrate durch Fällung mit verdünnter Schwefelsäure dargestellt, benützt. Es wurde mittelst überschüssigen Ammoniaks gefällt, und der neue Niederschlag durch Decantiren vollständig ausgewaschen.

1) Das Quecksilber ist hier, sowie bei dep folgenden Bestimmungen als Sulfid bestimut. Die Substanz wurde in Salzsäure, wo es nöthig war unter Zusatz von Chlorwasser, gelöst und die Lösung in Wasserbade zur Trockne eingedampft. Das trockne Salz wurde in Wasser gelöst und durch Schwefelwasserstoff gefällt. Nach kurzer Zeit wurde darauf der Niederschlag auf einem mit Salzsäure und Wasser ausgewaschenen, bei $100^{\circ}$ getrockneten und gewogenen Filtrum gesammelt, und nach vollständigem Auswaschen wurde das Ganze wieder bei $100^{\circ}$ getrocknet und gewogen, 
Der Luft ausgesetzt, verhält sich dieser Niederschlag ähnlich wie der vorhin besprochene. Auf einer Glasplatte ausgebreitet, nimmt er so bei $100^{\circ}$ im Laufe einiger Stunden eine weissgraue, oder wenn die Schicht ganz dünn ist, beinahe ganz weisse Farbe an, und ein ganz ähnliches Verhalten zeigt er sowohl im Lichte als im Dunkeln, wenn er einige Wochen der Luft bei gewöhnlicher Temperatur ausgesetzt wird. Die weisse Verbindung entwickelt beim Erhitzen mit Kalilauge reichlich Ammoniak und löst sich in verdünnter Salzsäure; die wenigen Flocken von. Quecksilberchlorür, die dabei ungelöst bleiben, rühren ohne $Z$ weifel ron geringen Spuren des ursprünglichen Niederschlages her, die von dem weissen Reste eingehüllt waren (vergl. S. 209). Ich fand, dass der Niederschlag einer Darstellung, bei welcher nur ein ganz geringer Ueberschuss an Ammoniak zur Anwendung kam, einen Gewichtsverlust von $43 \%$ bei $100^{\circ}$ und von $41,9 \%$ bei gewöhnlicher Temperatur erlitt; aus einer anderen Fällung, wo etwas melı Ammoniak verwendet wurde, erhielt ich ein Präparat, welches bei $100^{\circ} 42,4 \%$ verlor. Es weichen diese Zahlen nicht viel von denjenigen $a b$, die man erhalten sollte, wenn die Hälfte des Quecksilbers frei wäre und also verdunsten könnte. Nach $\mathrm{K}$ an e muss nämlich der Ammoniakniederschlag die Zusammen. setzung $\left.3 \mathrm{Hg}_{2} \mathrm{O}, \mathrm{SO}_{3}, \mathrm{Hg}_{2} \mathrm{~N}_{2} \mathrm{H}_{4}{ }^{1}\right)$ haben, und hiermit stimmen auch die Zahlen, die ich bei der Bestimmung von Quecksilber und Schwefelsäure darin erhielt; es wurden nämlich gefunden

1) Kane fand wohl in einigen Fällen, dass ungefähr die Hälfte, und nicht wie hier, drei Viertel der Schwefelsäure des Quecksilberoxydulsalzes an das Ammoniak übergetreten waren, und er vermuthet deswegen, dass es vielleicht auch zur Bildung eines Produktes der Zusammensetzung $\mathrm{Hg}_{2} \mathrm{O}, \mathrm{SO}_{3}, \mathrm{HgN}_{2} \mathrm{H}_{4}$ kommen kann (Ann. Chim. 72, 235). Diese Formel forilert $86,2 \%$ Quecksilber und $8,6 \%$ Schwefelsäure; wird sie, aus demselben Grunde wie oben, in $2 \mathrm{Hg}+\mathrm{HgO}, \mathrm{SO}_{3}, \mathrm{HgN}_{2} \mathrm{H}_{4}$ umgeschrieben, so würde der Gewichtsverlust, den der Nicdersehlag beim Verdunsten des freien Quecksilbers erleidet, zwar sehr gut mit dem gefundenen übereinstimmen, aber die zurickbleibende Verbindung sollte dam $15,2^{\circ}$ " Schwefelsäure statt $8,2^{\circ}: 0$, wie die Analyse ergab (siehe oben in der Fortsetzung des Textes) enthaiten. Uebrigens verdient es herrorgehoben zu werden, dass $K$ ane glaubt, dass die versehiedene Zusammensetzung des Nielerschlages darauf beruht, dass eine gewisse Menge Quecksilberoxyd beim Behandeln mit Ammoniak gebildet wird (a. a. 0.). 
$90,8 \%$ Quecksilber und $4,7 \%$ Schwefelsäure, wällrend die angeführte Formel $90,9 \%$, resp. $4, \tilde{5}^{0}{ }_{0}$ fordert. Die Hälfte des Quecksilbers ist also $4 \tilde{5}, 45^{\circ} \%$. Indem wir in der angegebenen Formel diesem Verhältniss Ausdruck geben, so wird dieselbe $=4 \mathrm{Hg}+3 \mathrm{HgO}, \mathrm{SO}_{3}, \mathrm{HgN}_{2} \mathrm{H}_{4}$, und das letzte Glied derselben soll dann die Zusammensetzung des weissen Restes ausdrücken, nachdem die $4 \mathrm{Hg}$ verdunstet sind; es ist aber nach $\mathrm{K}$ ane eben dies die Formel desjenigen Niederschlages, der aus dem schwefelsauren Quecksilberoxyd durch Fällung mit Ammoniak erhalten wird, und dem er den Namen "Ammonialsturpetlı" giebt. Damit stimmen auch einige ron mir ausgeführte Analysen des weissen Restes, den der Niederschlag (aus $\mathrm{Hg}_{2} \mathrm{SO}_{4}$ ) beim Erhitzen auf $100^{\circ}$ giebt; ich fand, dass er $84 \%_{0}$ Quechsilber und $8,2 \%$ Schwefelsäure enthielt, während die angeführte Formel $83,3 \%$ Quecksilber und $8,3 \%$ Scliwefelsäure rerlangt.

Uebrigens haben auch die am Schlusse der Besprechung des vorigen Niederschlages gemachten Bemerkungen hier ihre Gültigkeit. Wird nämlich nur auf die, zu einem späteren Zeitpunkte ausgeführte Analyse Rücksicht genommen, so kann es scheinen, als ob die Theilung des Quecksilbers, in einen freien flüchtigen und einen gebundenen nicht flüchtigen Theil, nicht genau nach der Hälfte stattgefunden hat. Bei dem oben erwähnten Niederschlage, der 90,8\% Quecksilber enthielt und bei $100{ }^{\circ} 43 \%$ an Gewicht verlor, also $57 \%$ weissen Restes hinterlies, wird, nach der mitgetheilten Analyse, das Verhältniss zwischen dem rerdunsteten und dem nicht verdunsteten Quecksilber wie 42,9:47,9 sein, also mit einer Abweichung von 2,5 zu beiden Seiten der Hälfte 45,4. Dieser Unterschied kann aber, nach allem was ich oben mitgetheilt habe, kaum $Z$ weifel darüber hervorrufen, dass der frische Niederschlag genau ebensoviel freies wie gebundenes Quecksilber enthält.

Der Ammoniakniederschlag des Quecksilberchlorürs.

$\mathrm{Zu}$ den nachfolgenden Versuchen habe ich diesen Niederschlag aus dem frisch gefällten, ausgewaschenen Chlorür dargestellt. Dieses wurde mit einer reichlichen Menge Wasser angerührt und mit A mmoniak im Ueberschuss zersetzt, und der neue Niederschlag durch Decantiren rollständig ansgewaschen. 
Wird dieser Niederschlag in frisch gefälltem, nur ausgewaschenem Zustande ganz dünn auf eine Glasplatte ausgebreitet und so in freier Luft bei gewöhnlicher Temperatur hingelegt, so nimmt er im Laufe einiger Tage eine weisse oder grauweisse Farbe an. Ganz wie beim Natronniederschlag ein gelber Ring um die dunkle Hauptmenge des Niederschlages gebildet wird, so tritt hier ein weisser Ring auf, der sich allmählich nach innen $z u$ verbreitet, in dem Maasse als das Quecksilber verdunstet. Die Schicht muss jedoch, um ganz weiss zu werden, sehr dünn sein; wenn dies nicht der Fall ist, so erbält sie nur einen granen Farbenton, hier und da vielleicht sogar mit kleinen dunklen Flecken. Bei längerem Liegen geht der graue Ton bisweilen in einen gelblichen über. Der weisse Rest verhält sich wie ,weisses Präcipitat" (Mercuriammoniumchlorid), u. a. auch darin, dass er beim Erhitzen in trockenem Zustande nicht schmilzt, dass er durch Behandeln mit Kalilauge Ammoniak entwickelt, dass er von kalter verdünnter Salzsäure, sowie von einer Lösung von Ammonnitrat, die etwas freies $\mathrm{NH}_{3}$ enthält, gelöst wird u. s. w. Wenn die Temperatur erhöht wird, so ändert sich die Farbe des ursprünglichen Niederschlages selbstverständlich etwas schneller, indem das freie Quecksilber dann leichter verdunsten kann. A uf einer Glasplatte in dünner Schicht aufgetragen, kann er z. B. bei ca. $50^{\circ}$ in einem Tage weiss oder grau werden, und bei $160^{\circ}$ verschwindet die dunkle Farbe noch schneller. Bei dieser Temperatur nimmt aber der Rest keine weisse, sondern eine hellgelbe Farbe an, die wohl als hellschwefelgelb oder citronengelb bezeichnet werden kann, ganz wie diejenige, die ein Gemisch von Mercuriammoniumchlorid und Quecksilber unter denselben Umständen annimmt (vergl. hierüber S. 215 u. 216). Kane giebt an ${ }^{1}$, dass der Niederschlag, den er durch starken Ueberschuss an Ammoniak erhalten hatte, der Luft ausgesetzt, keine Aenderung erleidet, und dass er gleichfalls weder Farbe noch Gewicht ändert, wenn or in einem Platintiegel einer Temperatur von $82^{\circ}\left(180^{\circ} \mathrm{F}\right.$.) ausgesetzt wird. Dies ist allerdings ein Irrthum, der aber sehr leicht passiren kann; was die Farbe betrifft, so erklärt derselbe sich dadurch, dass Ka n e den Nieder-

1) Pogg. Ann. 42, 380. 
Quecksilberoxydulsalze gegen Natron u. Ammoniak. 213 schlag als ganze Masse liegen liess, statt denselben in düuner Schicht lange Zeit auszubreiten, und in dem letzten Falle dadurch, dass er einen Tiegel, also ein ziemlich tiefes, vielleicht sogar geschlossenes Gefäss benutzte, wo das Quecksilber während der kurzen Dauer des Versuches keine genügende Gelegenheit zum Verdunsten gehabt hat. Auch ich habe gesehen, dass der Niederschlag beim Stehen in einem offenen Probeglase bei $100^{\circ}$ grösstentheils seine dunkle Farbs mehrere Tage lang behielt und nur die obersten Theile hell wurden. Unter solchen Verhältnissen verdunstet überhaupt das Quecksilber nicht leicht. Bei zwei Versuchen, wo Niederschläge aus verschiedenen Darstellungen auf Glasplatten dünn aufgetragen und ein paar Stunden bei $100^{\circ}$ in einen dunklen, der Luft leicht zugänglichen Raum gelegt wurden, bis sie gelb und das Gewicht constant geworden war, fand ich dagegen Gewichtsrerluste von $41,6 \%$ und $41,8 \%$. Nehmen wir an, dass auch dieser Niederschlag die Hälfte seines Quecksilbers in freiem verdunstbaren Zustande enthält, so müssten $44,3 \%$ verduısten ${ }^{1}$, was ja nicht sehr weit von dem Beobachteten liegt. Der schwefelgelbe Rest, der bei $100^{\circ}$ erbalten wird, ist nicht vollständig in verdünnter Salzsäure löslich, sondern hinterlässt eine kleine Menge Quecksilberchlorür. Dasselbe Verhalten zeigt auch ein bei $100^{\circ}$ gelb gewordenes Gemisch aus Quecksilber und Mercuriammonchlorid (vergl. S. 212 u. 216).

Dass der beobachtete Gewichtsverlust nicht von einer durch die Wärme hervorgerufenen Zersetzung der eigenthümlichen Verbindung, wofür man bisher nach $\mathrm{K}$ ane $u$. a. den Niederschlag gehalten hat, herrührt, geht daraus hervor, dass er auch bei gewöhnlicher Temperatur eintritt. Eine kleine Menge desselben Niederschlages, der bei $100^{\circ} 41,6^{\circ} \%$ an Gewicht verlor, wurde wie gewöhnlich auf einer Glasplatte ausgebreitet und, indem sie gegen starkes Licht geschützt wurde, unter freiem Zutritt der Luft hingelegt. Die Kanten desselben wurden zuerst grauweiss, und als nach ungefähr 4 Wochen das Ganze weiss mit einem gelblichen Schimmer geworden war, hatte er genau ebensoviel wie bei $100^{\circ}$, nämlich $41,6 \%$

t) $\mathrm{Hg}_{2} \mathrm{H}_{2} \mathrm{NCl}=\mathrm{Hg}+\mathrm{HgH}_{2} \mathrm{NCl}$, oder 451 Gewichtstheile des Niederschlages enthalten 200 Fewichtstheile foien Quecksilber. 
an Gewicht verloren. Es leuchtet ein, dass dieser grosse Gewichtsverlust nur durch Verdunsten von Quecksilber bedingt sein kann, da die elementare Zusammensetzung des Niederschlages der Formel $\mathrm{Hg}_{2} \mathrm{H}_{2} \mathrm{NCl}$ entspricht, und nach Allem, was schon mitgetheilt ist, scheint es beinahe unnöthig, $\mathrm{zu}$ bemerken, dass Farbenänderung, Gewichtsverlust und Verdunsten des freien Quecksilbers gleichmässig vorschreiten. Man kann dies sehr leicht verfolgen, wenn ein Glasstreifen mit dem ausgebreiteten Niederschlage in ein geräumiges Gefäss, dessen Boden mit Goldchloridlösung bedeckt ist, gebracht wird. (Vergl. S. 207.)

Aus dem hier Mitgetheilten geht hervor, dass der Niederschlag, welchen man aus Queclssilberchlorïr durch Zusatz von überschüssigem Ammoniak erhält, nnd der wohl bisher vor allen anderen Ammoniakniederschlägen der Quecksilberoxydulverbindungen für eine ganz bestimmt charakterisirte Verbindung angesehen wurde, nichts als ein Gemisch von $\mathbf{H g}$ mit $\mathrm{HgH}_{2} \mathrm{NCl}$ ist.

Hieran knüpfen sich einige Fragen, die einer näheren Erklärung bedürten. Wenn der Niederschlag nämlich nur ein Gemisch ist, weshalb besitzt dann der Rest, den er beim Liegen an der Luft hinterlässt, statt der rein weissen Farbe des Mercuriammoniumchlorids bisweilen eine gelbliche (S. 212) Farbe? und weshalb wiegt dieser Rest stets etwas mehr, als nach der Berechnung zu erwarten war? (S. 213.) Die Antwort hierauf ist die folgende: Weil während des Liegens des Niederschlages die beiden Bestandtheile desselben, das freie Quecksilber und das Mercuriammoniumchlorid, auf einander einwirken, wobei neue Produkte entstehen, darunter Quecksilberchlorür und eine gelbe Verbindung. Dass dies der Fall und also keine Ursache dazu vorhanden ist, in dem ursprünglichen Niederschlage andere Bestandtheile als die genannten anzunehmen, geht aus dem folgenden Versuche hervor: In einem Porzellanmörser wurden reines Quecksilber und "weisses Präcipitat" zusammengerieben, und die Mischung in einem nur schwach beleuchteten Raume unter eine lose schliessenden Glasglocke gestellt. Das hierzu verwendete Mercuriammonchlorid war auf gewöhnliche Weise dargestellt, sorgfältig ausgewaschen und getrocknet. Im Laufe von 5 Wochen, in welcher Zeit die Masse hin und wieder 
Quecksilberoxydulsalze gegen Natron u. Ammoniak. 21 j

aufs neue gut durchgemischt wurde, nahm sie nach und nach einen immer deutlicher hervortretenden grünlichgelben Ton an. Das Gemisch wurde darauf in Wasser suspendirt, und durch Schlämmen wurden dabei erhalten 1. ein heller leichterer Theil und 2. ein dunkler Theil, welcher noch kleine Quecksilberkugeln enthielt. Ersterer besass eine grünlichgelbe Farbe, doch mit einem wahrscheinlich von einer kleinen Menge fein vertheilten Quecksilbers herrührenden grauen Schimmer. Beim Liegen an der Luft bei gewöhnlicher Temperatur wurde die Farbe des Pulvers denn auch reiner, und nach 6 Wochen war dieselbe schön gelb; während dieser Zeit hatte das Produkt $12,5 \%$ an Gewicht verloren. Hieraus folgt, dass die oben erwähnte Thatsache, wonach der schwarze Ammoniakniederschlag des Quecksilberchlorürs beim Zutritt der Luft einen Rest von gelblicher Farbe hinterlassen kann, keineswegs mit der Annahme, er bestehe ursprünglich allein aus Quecksilber und Mercuriammonchlorid, im Widerspruch steht, und dass er nur dann einen rein weissen Rest hinterlassen kann, wenn er so dünn ausgebreitet ist, dass das Quecksilber ganz ungehindert verdunsten kann (S. 212).

Zur Beantwortung der zweiten Frage lies ich das gelbe Pulver, welches $12,5 \%$ an Gewicht verloren hatte, diann ausgebreitet an freier Luft, bei gewöhnlicher Temperatur und gegen Licht geschützt, noch 3 Monate stehen, und da sich sein Gewicht während dieser Zeit nicht mehr änderte, so könnte angenommen werden, dass es kein freies Quecksilber mehr enthielt und also für die folgende Prüfung, welche besonders darauf gerichtet sein müsste, Quecksilberchlorür nachzuweisen, geeignet war. Der Nachweis von Quecksilberchlorür wäre nämlich, falls noch metallisches Quecksilber vorhanden, vollständig bedeutungslos, da in diesem Falle das freie Quecksilber mit dem jedenfalls anwesenden Quecksilberchlorid Chlorür bilden würde. Die Prüfung bestand darin, dass das gelbe Pulver mit ziemlich verdünnter Salzsäure (spec. Gew. 1,035) übergossen und bei gewöhnlicher Temperatur unter fleissigem Umschïtteln hingestellt wurde. Im Laufe einiger Stunden verschwand die gelbe Farbe und ein Theil des Pulvers wurde gelöst, es blieb aber auch ein weisser Rest in recht ansehnlicher Menge zurūck. Die filtrirte Lösung gab mit Natron- 
lauge einen weissen Niederschlag, und das dabei erhaltene Gemisch entwickelte Ammoniak, als es mit Schwefelnatrium erhitzt wurde; mit Jodkalium gab sie einen rothen Niederschlag u. s. w., sie verhielt sich also wie eine salzsaure Lösung von Mercuriammoniumchlorid. Der weisse, ungelöste und sorgfältig ausgewaschene Rest dagegen wurde durch Behandeln sowohl mit Natronlauge als mit Ammoniakwasser schwarz und nalım durch Einwirkung von Jodkalium eine gelbgrüne Farbe an, d. b. er verhielt sich wie Quecksilberchlorür. In einem aus Quecksilber und Mercuriammoniumchlorid bereiteten Gemisch geht also ein Theil des freien Quecksilbers in die gebundene Form. besonders als Chlorür, über, und es leuchtet demnach ein, dass auch in dem schwarzen Ammoniakniederschlag des Quecksilberchlorürs das freie Metall während des Liegens des Niederschlages an der Luft die Bildung ron Quecksilberchlorür veranlasst, und dass der Gewichtsverlust des Niederschlages folglich nicht der ganzen Menge des freieu Quecksilbers entsprechen kann (S. 213 u. 209).

Dieselbe Aenderung, welcher ein solches Gemisch bei gewöhnlicher Temperatur unterliegt, findet auch in der Wärme statt, nur verläuft dieselbe dann viel schneller. Beim Liegen in einem der Luft zugänglichen Raume bei $100^{\circ}$ verlor das oben erwähnte grünlichgelbe Pulver bald den grauen Schimmer, und nach 24 Stunden war es hell citronengelb und verhielt sich gegen kaltc verdünnte Salzsäure ganz wie oben (S. 213).

Die Frage, welche Verbindung dem so gebildeten gelben Produkte zu Grunde liegt, wird bei einem Gemisch wie dem vorliegenden, welches zugleich Quecksilberchlorür und wohl auch unverändertes Mercuriammonchlorid enthält, schwer zu entscheiden sein, hat aber auch für die vorliegende Untersuchung wenig Bedeutung. Es liegt nahe, anzunehmen, dass die Verbindung $\mathrm{HgH}_{2} \mathrm{NCl}, \mathrm{HgO}$ gebildet wird, und was ihre Entstehungsweise betrifft, so muss in Betracht gezogen werden dass gleichzeitig nicht nur, wie schon erwähnt, Quecksilberchlorür, sondern auch freies Ammoniak gebildet wird. Dass Ammoniak entsteht, ist leicht nachzuweisen; reibt man nämlich in einem Porzellanmörser Quecksilber mit Mercuriammoniumchlorid zusammen und deckt das Gemisch mit einer Glasplatte zu, auf deren Unterseite ein befeuchtetes Curcuma- 
Quecksilberoxydulsalze gegen Natron ù. Ammoniak. 217 papier oder ähnliches befestigt ist, so dauert es nur 10-15 Minuten, bis die alkalische Reaction hervortritt. Aehnlich verhält sich auch der schwarze Ammoniakniederschlag des Quecksilberchlorür; in halbtrocknem Zustande in einer Schale mit Glasplatte u. s. w. angebracht, giebt auch er die alkalische Reaction, ein neuer Beweis für die Uebereinstimmung beider Gemische. Doch ist die bei diesen Mischungen beobachtete Ammoniakentwicklung bedeutend schwächer als diejenige, welche bei einem Gemisch von Quecksilber und Chlorammonium stattfindet (s. unten S. $222-223$ u. f.). Nach dem Angeführteu kann man sich nun vorstellen, dass die Reaction entweder in $z$ wei Stufen verläuft, so nämlich, dass zuerst aus $2 \mathrm{HgH}_{2} \mathrm{NCl}$ und $\mathrm{H}_{2} \mathrm{O}: \mathrm{NH}_{4} \mathrm{Cl}$ und $\mathrm{HgH}_{2} \mathrm{NOl}, \mathrm{HgO}$ entstehen (also dieselbe Reaction, welche stattfindet, wemn man nach $\mathrm{Kane}$,weisses Präcipitat" mit Wasser kocht, bis es gelb wird) und darauf das entstandene Chlorammonium auf das freie Quecksilber einwirkt (S. 223 Anm.) - oder dass sie, wie es die Gleichung:

$$
2 \mathrm{Hg}+4 \mathrm{HgH}_{2} \mathrm{NCl}+\mathrm{H}_{2} \mathrm{O}+\mathrm{O}=\mathrm{Hg}_{2} \mathrm{Cl}_{2}+2\left(\mathrm{HgH}_{2} \mathrm{NCl}, \mathrm{HgO}\right)+2 \mathrm{NH}_{3}
$$

ausdrückt, ohne Abstufungen verläuft. Wenn das gelbe Produkt in der That die hier angenommene Zusammensetzung hat und auf die angeführte Weise entsteht, so sind die Gewichtsmengen des in Reaction getretenen Wassers und Sauerstoffs und des gebildeten Ammoniaks genau gleich gross.

An die obige Mittheilung über den Ammoniakniederschlag des Quecksilberchlorürs knüpfe ich noch eine zweite über das sogenannte

$$
\text { Quecksilberchlorür-Ammoniak }
$$

welches von $\mathrm{H}$. Rose ${ }^{1}$ ) durch Einwirkung von trocknem Ammoniak auf trocknes Quecksilberchlorür dargestellt wurde, und dessen elementare Zusammensetzung nach ihm durch die Formel $\mathrm{Hg}_{2} \mathrm{Cl}_{2} \mathrm{~N}_{2} \mathrm{H}_{6}$ ausgedrückt wird. Meine Untersuchung dieses Produktes gab das Resultat, dass es nur darin von dem Ammoniakniederschlage verschieden ist, dass es Chlorammonium entbält.

1) Seine Mittheilung hierüber ist $S .159$ in der Abhandlung "Ueber die Verhindungen des Ammoniaks mit wasserfreien Salzen". Pogg. Ann. 20, 14t-164, zu finden. 
Zur Darstellung des Quecksilberchlorür-Ammoniaks habe jch, wie Rose, gefälltes Quecksilberchlorür angewandt. Dieses wurde bei $100^{\circ}$ getrocknet und in demselben Rohre, in welchem es später der Einwirkung des Ammoniaks ausgesetzt werden sollte, gewogen. Bei jedem Versuche wurden ungefähr $1^{1 / 2} \mathrm{Grm}$. oder dieselbe Menge, die Ros e verwendete, in Arbeit genommen. Das eine Ende der Röhre wurde darauf mit dem Trockenapparate für das Ammoniakgas, das andere, damit der Inhalt der Röhre gegen die Feuchtigkeit der Luft geschützt sei, mit einer U-Röhre mit Kalihydrat verbunden. Das Ammoniakgas wurde aus Salmiak und Kalk entwickelt und zuerst (damit die Intensität der Entwicklung controllirt werden konnte) durch eine Liebig'sche Kugelröhre mit Ammoniakwasser ge. leitet, daraut ging es durch ein aufrecht stehendes Glas mit gebranntem Kalk und endlich durch mehrere $\mathrm{U}$-förmige Kaliröhren von ansehnlicher Weite und deren Gesammtlänge über einen Meter betrug, ehe es in die Reactionsröhre trat. Die Gasentwicklung wurde so geleitet, dass in jecler Secunde ein par? Luftbläschen durch die Flüssigkeit in der Kugelröhre gingen und bis 10 Stunden fortgesetzt. Die letzte der Kaliröhren hatte dann nur 11/2 Milligrm. an Gewicht zugenommen. Das Queckilberchlorür wurde wohl bald dunkler, da es aber bei einigen auf diese Weise ausgeführten Versuchen erst sehr spät ganz àunkel wurde und nur wenig an Gewicht zunahm, bei einem Tersuche nabm es z. B. in 5 Stunden nur $1,67 \%$, oder nur ein Viertel von dem, was die Rose'sche Formel fordert, an Gewicht zu, wurde ich aut den Gedanken gebracht, dass die Absorption vielleicht bei niedrigerer Temperatur leichter. verliiuft. Es wurde deswegen eine leere, zweihalsige Flasche und eine Schlangenröhre zwischen der Kugelröhre und dem Trockenapparate eingeschaltet, und sowohl diese als die nächstletzte Kaliröhre und die Reactionsröhre mit Eis umgeben. Dadurch wurde im Laufe von 5 Stunden eine Gewichtszunahme von $4,38 \%$, und in 10 Stunden von $6,97 \%$ erreicht. Ich labe indessen gefunden, class die allgemeine Beschaffenheit des Produktes sich sehr deutlich zu erkennen giebt, wenn auch die Absorption hinter den berechneten $7,22 \%$ zurückbleibt.

Wenn Rose die Reaction einfach als eine Absorption von A mmoniak auffasst, ohne die Möglichkeit einer Zersetzung 


\section{Quecksilberoxydulsalze gegen Natron u. Ammoniak. 219}

des Quecksilberchlorürs anzudeuten, so muss daran erinnert werden, dass seine Untersuchung in eine Zeit fällt, wo die Kenntniss von der Einwirkung des Ammoniaks auf die Quecksilberoxydulsalze noch sehr mangelhaft war, und besonders dass Kane's Arbeit über den Ammoniakniederschlag des Quecksilberchlorürs erst einige Jahre später veröffentlicht wurde (vergl. S. 212). Der Schluss seiner Abhandlung zeigt, dass er, bis auf wenige Ausnahmen, die neuen Verbindungen, die er in nicht geringer Anzahl auf ähnliche Weise erhielt, für directe Verbindungen der in Reaction getretenen Stoffe, analog seinen „Wasserverbindungen wasserfreier Salze“, ansieht und demnach fasst er denn auch das vorliegende Produkt direct als "Quecksilberchlorür-Ammoniak" auf. Und ebenso einfach wie also nach seiner Ansicht die Verbindung gebildet wird, kann sie nach ihm wieder zersetzt werden, denn das neue Produkt verliert bei schwachem Erhitzen seine schwarze Earbe, indem es Ammoniak abgiebt, und ,hinterlässt also reines, ungeändertes Quecksilberchlorür"; ebenfalls wird es bei langem Liegen an der Luft weiss ${ }^{1}$, ,indem das Ammoniak vollständig entweicht". $\left.{ }^{2}\right)$ Soweit mir bekannt, hat auch späterhin Niemand die Vermuthung geäussert, dass besagtes Produkt möglicherweise doch mit dem Ammoniaknierlerschlage übereinstimme. ${ }^{3}$ ) Der anscheinend bedeutende Unterschied zwischen beiden Substanzen, dass die eine, nach $\mathrm{R}$ ose, beim Liegen an der Luft nuter Abgabe von Ammoniak weiss wird, die andere dagegen, nach Kane, sich dabei nicht ändert (was jedoch, wie ich

2) Ganz weiss wird der Rest jedoch gewöhnlich nicht; er bekommt meist einen gelblichen Farbenton. Dies rührt wahrscheinlich von einer geringen $\mathrm{Menge} \mathrm{HgH}_{2} \mathrm{NCl}, \mathrm{HgO}_{\mathrm{g}}$ her, welches durch die Einwirkung des freien Quecksilbers auf Mercuriammonehlorid entsteht. Auf das Auftreten der letzteren Verbiudung in diesem Produkte komme ich unten (S. 223) zurück. Die Farbe des Restes ist wohl am besten ganz allgemein als "bell" zu bezeichnen.

2) Rose sagt allerdinge nicht ausdrücklich, dass der Rest auch in diesem Falle aus Quecksilberchlorür besteht, nach der Wortstellung muss man aber annehmen, dass dies seine Meinung ist, eine Meinung, die übrigens, wie ich unten $\mathrm{S}$. 225 zeigen werde, unrichtig ist.

3) Isambert, der i. J. 1868 eine Untersuchung über die Dissociation der Ammoniakverbindungen einiger Chlormetalle, darunter auch des Quecksilberchlorürammoniaks, veröffentlicht hat, führt nichts an, das auf eine solche Vermuthung deuten könnte (Compt. rend. 65, 1259). 
oben S. 212 nachgewiesen habe, auf Irrthum beruht; vergl. auch S. 217 oben, wo eine Abgabe von Ammoniak constatirt wurde) lässt auch kaum einen $Z_{\text {weifel an ihrer Verschiedenheit }}$ aufkommen. Schade nur, dass Rose nicht den Gewichtsrerlust seines Produktes beim Liegen an der Luft oder bei schwachem Erwärmen bestimmte; es würde dann gewiss nicht seiner Aufmerksamkeit entgangen sein, dass derselbe grösser als die Gewichtszunahme des Chlorürs ist, und dass also die Reaction eine complicirtere ist, als von ihm angenommen. Ich beschränke mich, was diese Frage betrifft, darauf, mitzutheilen, dass der Gewichtsverlust sich auf mehr als das dreifache der vorausgehenden Gewichtszunahme belaufen kann. Auch würde $\mathbf{R}$ o se, wenn er untersucht hätte, ob etwas des weissen Restes in Salzsäure löslich wäre, die Erfahrung gemacht haben, dass derselbe keineswegs aus ,reinem ungeänderten Quecksilberchlorür" besteht; verg]. S. 225.

Ich habe schon oben bemerkt, dass das schwarze Produkt im Wesentlichen mit dem Ammoniakniederschlage des Quecksilberchlorürs übereinstimmt, und mit Rücksicht darauf constatire ich zuerst, dass es freies Quecksilber enthält. Ich fand nämlich, dass Goldblech stark amalgamirt wurde, als das Produkt, gleich nachdem es aus der Absorptionsröhre herausgenommen war, mittelst eines Glasstabes darauf ausgebreitet wurde; und als eine kleine Menge desselben (0,24 Grm. des S. 218 erwähnten Produktes, dessen Gewichtszunahme nur $1,67^{\circ} \%$ betrug) unter cine kleine Glasglocke neben eine Porzellanschale mit Goldchloridlösung, die mit Rücksicht atuf das entweichende Ammoniakgas mit etwas Salzsäure angesüuert war, gebracht wurde, so dauerte es nicht lange, bis eine Reduction des Goldchlorids zu bemerken war, uld nach 24 Stunden hatte sich auf den Wandungen der Schale, längs der Oberfläche der Flüssigkeit, ein Ring aus blankem Golde gebildet. Als bei fortgesetztem Stehen unter der Glocke die Goldchloridlösung durch eine Silbernitratlösung ersetzt wurde. gab dieselbe Probe des Produktes noch eine Ausscheidung ron reducirtem Silber. (Vergl. über den Natronniederschlag der Quecksilberoxydulsalze dies. Journ. [2] 38, 465.) Dass diese Reduction in der That von Quecksilberdämpfen herrülnte. wurde durch den Nachweis ron Quecksilber in beiden Lösungen 
bewiesen. Die Lösungen wurden zu diesem Zwecke mit Natriumcarbonatlösung eingetrocknet, und der Rückstand in engen Probirgläsern erhitzt (bei der Goldchloridlösung hatte sich hierbei etwas Knallgold gebildet, welches einige kleine Ver. puffungen verursachte, sonst aber den Versuch nicht störte). Der Quecksilberbeschlag konnte bei der kleinen in Arbeit genommenen Menge selbstverständlich nur sehr schwach 6ein, er gab sich aber in beiden Fällen sehr deutlich zu erkennen, als ein kleines Jodkörnchen in den obersten Theil des abgekühlten und schräg gestellten Glases gebracht wurde. Nach einer. Viertelstunde war der Beschlag roth und bei darauf folgendem Erhitzen sublimirte das rothe Quecksilberjodid mit gelber Farbe, um wieder nach der Abkühlung durch Streichen mit einem Glasstabe die ursprüngliche rothe Farbe anzunehmen. Es steht demnach fest, dass das schwarze Produkt freies Quecksilber enthält.

Wenn aber freies Quecksilber durch lie Einwirkung von gasförnnigem Ammoniak auf trocknes Quecksilberchlorür eutsteht, so ist es ganz natürlich, dass auch Chlorammonium entsteht. Beim Ausziehen des schwarzen Produktes mit kaltem Wasser, Filtriren und Zusatz von Silbernitrat zu dem Filtrate, erhielt ich denn auch einen starken Niecierschlag vou Chlorsilber, und dass dieses nicht vou einer löslichen chlorhaltigen Quecksilberverbindung herrührt, geht daraus hervor, dass selbiges Filtrat durch Schwefelwasserstoff nur sehr schwach gefürbt wurde. (Vergl. S. 223 Anm.) Hierbei übersehe ich nicht, dass dies kein unumstösslicher Beweis für die Anwesenheit fertig gebildeten Chlorammoniums in dem schwarzen Produkte ist; man könnte sich ja vorstellen, dass dieses schwarze Produkt durch das zugesetzte Wasser derart zersetzt wird, dass Chlorammonium und der gewöhnliche Ammoniakniederschlag entstehen. Der Thatsache gegenüber, dass das schwarze Produkt ursprünglich freies Quecksilber enthält und also keine Quecksilberoxydulverbindung sein kann, erscheint aber diese Vorstellung, mit meiner ganz einfacken Deutung verglichen, als ein wenig gelungener Versuch, eine vermuthete Verbindung aufrecht zu erhalten, und jedenfalls würde dann die Frage zu beantworten sein, was denn diese quecksilberärmere Verbindung sei. 
Mit Bezug auf das Vorhergehende und alles was sonst über die Fähigkeit des Quecksilbers, Amidverbindungen und dergleichen zu bilden, bekannt ist, nelime ich deshalb an, dass das schwarze Produkt dadurch entsteht, dass $\mathrm{Hg}_{2} \mathrm{Cl}_{2}$ and $\mathrm{N}_{2} \mathrm{H}_{6}$ sich in $\mathrm{NH}_{4} \mathrm{Cl}+\mathrm{Hg}+\mathrm{HgH}_{2} \mathrm{NOl}$ umsetzen, d. h. die Reaction ist dieselbe, wie bei der Bildung des Ammoniakmiederschlages und die Produkte sind nur darin verschieden, dass das sogenannte "Quecksilderchlorür-Ammoniak" das gebildete Chlorammonium noch enthält, der Ammoniakniederschlag dagegen nicht. Dass die Umsetzung auf dem trocknen Wege nur langsam verläuft, kann nicht überraschen; denn das Quecksilberchlorür bildet nach dem Trocknen ein ziemlich klumpiges Pulver, und da dieses noch während des Versuches ruhig liegt, kann das Ammoniakgas dasselbe nur schwer durchdringen.

Damit aber das schwarze Produkt mit Recht für ein solches Gemisch, wie oben angenommen, angesehen werden kann, muss noch nachgewiesen werden, dass seine sonstigen Eigenschaften mit dieser Annahme übereinstimmen. Dieser Nachweis wird im Folgenden gebracht werden,

Dass es beim Liegen an der Luft Ammoniak entwickelt, rührt davon her, dass das freie Quecksilber auf die beiden andern Bestandtheile zersetzend einwirkt, besonders aber auf das Chlorammonium, womit es unter Mitwirkung ron Sauerstoff Quecksilberchlorür, (vergl. 223 Anm.) Ammoniak und Wasser bildet. Eine solche Reaction erscheint allerdings auffallend; man überzeugt sich aber leicht daron, duss sie nicht nur möglich ist, sondern auch riemlich leicht eingeleitet wird. Reibt man nämlich in einem Porzellanmörser Quecksilber und trocknes Chlorammonium zusammen, so macht sich das Ammoniak bald bemerkbar. Wird der Mörser mit einer Glasplatte zugedeckt, auf deren Unterseite die gewöhnlichen Reagenzpapiere mittelst einiger $W$ assertropfen angebracht sind, dann tritt die alkalische Reaction schon nach wenigen Augenblicken hervor, und wenn man, nachdem das Ganze ungefähr eine Stunde gestanden hat, die Glasplatte wegnimmt, so kann man das Ammonial deutlich riechen. Nach einigen Tagen wird die Entwicklung von Ammoniak allerdings schwächer, kann aber durch erneutes Zusammenreiben der Masse wieder intensiver gemacht werden. Es ist schon oben (S. 216) erwähnt, 
dass auch bei der Einwirkung von Quecksilber auf den zweiten Bestandtheil des schwarzen Produktes, nämlich das Mercuriammoniumchlorid, Ammoniak entsteht, auf dieses wirkt es aber bedeutend schwächer als auf Salmiak ein.

Durch diesen Uebergang des freien Quecksilbers in gebundenes ${ }^{1}$ ) erklärt es sich auch leicht, dass dieses schwarze

1) Was überhaupt alles beim Stehen eines pulverförmigen Gemisches aus Quecksilber und Salmiak an der Luft gebildet wird, ist nicht leicht zu entscheiden; aus dem Folgenden geht aber hervor, dass ausser Ammoniak und Wasser wenigstens Quecksilberchlorür und Mercuriammoniumchlorid - oder eine ähnliche Verbindung - entstehel. Eisteres entsteht wohl wach der Gleichung:

$$
2 \mathrm{Hg}+2 \mathrm{NH}_{4} \mathrm{Cl}+\mathrm{O}=\mathrm{Hg}_{2} \mathrm{Cl}_{2}+2 \mathrm{NH}_{3}+\mathrm{H}_{2} \mathrm{O}
$$

und letzteres vielleicht dadurch, dass ein Theil des gebildeten Quecksilberchlorürs sich mit dem gebildeten Anmoniak umsetzt, oder vielleicht direct, indem

$$
\mathrm{Hg}+\mathrm{NH}_{4} \mathrm{Cl}+\mathrm{O}=\mathrm{HgH}_{2} \mathrm{NCl}+\mathrm{H}_{2} \mathrm{O} \text {. }
$$

Für die Bildung dieser beiden Verbindungen, von welchen das Chioriir als die vorherrschende angesehen werden muss, spricht folgendes.

Ich liess das graue Pulver, welches in einem Porzellanmörser durch Zusammenreiben von ungefähr 2 Thln. reinen Quecksilbers und 1 Tł:L. Salmiak erhalten war, beinahe+14 Tage lose zugedeckt bei gewöhnlicher Temperatur stehen. Während dieser Zeit wurde die Masse hin und wieder aufs neue sorgfältig durchgemischt. Es wurde danach, zur Entfernung des unvertanderten Salmiaks, kaltes Wasser zugesetzt, abfiltrirt und der Rückstand mittelst kalten Wassers ausgewaschen. Obgleich das Ganze nur ein parr Gramm betrug und das Auswaschen viel länger, als zur Entferuung einer so kleinen Menge Chlorammonium sonst nöthig ist, fortgesetzt wurde, gab das Waschwasser doch fortwährend Reaction mit Silbernitrat, und nahm nach Einleiten von Schwefelwasserstoff eine braune Farbe an. Diese Reactionen konnten weder ron Quesksilberchlorür, da dies in Wasser völlig unlöslich ist, noch von Quecksilberchlorid, da dieser so leicht löslich ist, dass es schon längst entfernt sein müsste, herrühren. Ein Theil des so ausgewaschenen Pulvers wurde mit starker Kalilauge behandelt. Es nahm dabei gleich eine schwarze Farbe an, welche auf Quecksilberchlorür deutet, und beim Erbitzen entwickelte das alkalische Gemisch Ammoniak, indem der Niederschlag gleichzeitig etwas heller wurde, Umstände, die auf Mercuriammonchlorid oder ähnliches deuten. Der ïbrige Theil des ausgewaschenen Pulvers wurde in ein Becherglas gebracht und mit Wasser geschlämmt; es wurden dabei ein dunkler Rest, der noch unverindertes Qnecksilber enthielt, und eine milchige Flüssigkeit erhalten. Letztere setzte beim Stehen ein beinahe weisses Pulver in ziemlich reichlicher Menge ab. Beim Bebandeln mit starker Kalilauge wurde dieses Pulver schwarz (Quecksilberchlorïr) und beim Erlhitzen 
Produkt bein Stehen unter einer Glocke mit Schwefelsäure weiss oder vielmehr "hell" werden kamn (S. 219 Anm.), dem da das freigemachte Ammoniak nach und nach von der Schwefelsäure absorbirt wird, und da ferner die Bestandtheile in solchem Verhältnisse yorhanden sind, dass alles Quecksilber gebunden werden kann, so wird die Reaction durch nichts gehindert. Anders mit dem ausgewaschenen, also chlorammoniumfreien Ammoniakniederschlage des Quecksilberchlorürs, der unter diesen Umständen dunkel bleibt; er kann nicltt weiss werden, denn das freie Quecksilber kann nicht verdunsten dies kann dagegen unter einer Glocke mit Goldchlorid geschehen) und da er zweimal soviel Quecksilber enthält, als von dem Mercuriammoniumchlorid allein gebunden werden kann, so kann er auch nicht gelb werden.

Dass der Gewichtsverlust des schwarzen Pulvers beim Zutritt der Luft grösser ist als die Gewichtszunahme des Quecksilberchlorürs im Ammoniakgase, wird ganz einfach dadurch erklärt, dass nicht nur Ammoniak entweicht, sondern auch Quecksilber verdunstet. Es ist auch leicht einzusehen, dass die Grösse des Gewichtsverlustes in jedem einzelnen Falle von den näheren Umständen während des Versuches abhängt; denn je nachdem die in Arbeit genommene Menge des Pulvers in mehr oder weniger dünner Schicht ausgebreitet ist, und je nach der Temperatur, der dieselbe ausgesetzt ist, wird die besprochene Reaction zwischen Quecksilber und Salmiak in verschiedenem Umfange sich vollziehen und also eine verschiedene Menge des freien Metalls gebunden werden können.

Dass der helle Rest, den das schwarze Produkt bei Luftzutritt hinterlässt, ausser Quecksilberchlorür noch eine bedeutende Menge einer anderen Quecksilberverbindung enthält, ist daraus ersichtlich, dass er, nachdem ein möglicherweise

damit entwickelte es Ammoniak (Mercuriammoniumchlorid). Mit Jodkalium übergossen, nahrn es eine gelblichgrüne Farbe an (Quecksilberehlorür). Endich wurde ein Theil davon 5 Minuten mit kalter, verdiinnter Salzsüure (spec. Gew. $=1,035$ ) geschüttelt und das Gelöste abfiltrirt. Das Filtrat gab mit Schwefelwasserstoff gleich einen Niederschlag, enthielt also Quecksilber, und gab durch Erhitzen mil starker Kalilauge, sowohl allein als unter Zusatz von vatriumsulfhydrat, eine deutliche Entwicklung von Ammoniak. Dieses Verhalten gegen Salzsäure u. s. w. spricht entschieden dafür, dass Mercuriammoniumchlorid in dem Pulver enthalten ist. 
vorhandener Rest von Chlorammonium durch Auswaschen mit Wasser entfernt ist, in kalter verdünnter Salzsäure (spec. Gew. $=1,035$ ) theilweise löslich ist. Der weisse, ungelöste Rest verhält sich wie Quecksilberchlorür. Die Lösung dagegen gab mit Ammoniak einen starken, weissen, mit Jodkalium einen starken, rothen Niederschlag; mit Schwefelwasserstoff gab sie einen reichlichen Niederschlag, und wurde danach Natron zugesetzt und erwärmt, so wurde Ammoniak entwickelt. Alles dieses deutet darauf hin, dass das Pulver Mercuriammoniumchlorid in ausehnlicher Menge enthält, und zeigt, wie fern es davon ist, „reines Quecksilberchlorür" zu sein, wie Rose meint (S. 219).

Damit, dass Mercuriammoniumchlorid vorhanden ist, stimmt auch sehr gut überein, dass beim Auswaschen sowohl des schwarzen Produktes als des hellen Restes die Waschwasser sehr lange auf Silbernitrat reagiren; denn jene Verbindung ist bekanntlicher. Weise nicht vollständig unlöslich in Wasser. (Vergl. auch S. 223 Anm.)

Rose giebt ferner an, dass das schwarze Produkt durch Behandeln mit Salzsäure in Quecksilberchlorür umgebildet wird. Auch dieses stimmt mit dem Verhalten eines Gemisches der angegebenen Art überein; die Reaction besteht aber nicht, wie er meint, einfach darin, dass die Säure das Ammoniak aufnimmt und das Chlorür zurücklässt, sondern darin, dass sie das Mercuriammoniumehlorid löst, worauf die entstandene Lösung mit dem freien Quecksilber Quecksilberchlarür bildet (vergl. Natronniederschlag S. 449). -- Hieraus ist ersichtlich, dass die Umsetzung beim Erhitzen des schwarzen Produktes, wobei nach Rose Ammoniak weggeht und Quecksilberchlorür zurückbleibt, weniger einfach ist, als von ihm angenommen.

Der Ammoniakniederschlag des oxalsauren Quecksilberoxyduls.

Zur Darstellung dieses Niederschlages habe ich, wo nichts anderes angegeben ist, oxalsaures Quecksilberoxydul verwendet, das durch Fällung einer verdünnten Lösung des Nitrates mit einer Oxalsäurelösung dargestellt war. Der weisse Niederschlag wurde gleich nach dem Auswaschen durch Ammoniak Journal f. prakt. Chemie [2] Bd. 39. 
in Ueberschuss zersetzt, und nach kurzem Stehen wurde das schwarzgraue Produkt sorgfältig ausgewaschen.

Bevor ich auf die Aenderung des Niederschlages unter Zutritt von Luft ubergehe, theile ich einige Versuche mit, die dazu dienen sollten, das Verhältniss zwischen den Bestandtheilen derselben zu bestimmen. ${ }^{1}$ )

Das Verhältniss zwischen Oxalsäure und Amid (oder dem demselben entsprechendem Ammoniak) lies sich leicht bestimmen.

Der ausgewaschene Niederschlag gab nämlich nach Schütteln mit Schwefelwasserstoffwasser im Ueberschuss eine Lösung von neutralem oxalsaurem Ammoniak. Das blaue Lackmuspapier wurde allerdings durch Einwirkung des Schwefelwasserstofts gleich roth, aber nachdem es einen Augenblick der Luft ausgesetzt gewesen war, wobei der $\mathrm{H}_{2} \mathrm{~S}$ wegging, wurde es wieder blau. Curcumapapier wurde von der Flüssigkeit nicht verändert. Es ist hieraus ersichtlich, dass der Niederschlag, als Amidverbindung aufgefasst, für jedes Molekül Oxalsäure 2 Aınidgruppen enthalten muss.

Das Verhältniss zwischen Oxalsäure und Quecksilber habe ich dadurch bestimmt, dass ich zuerst oxalsaures Quecksilber-

1) Harff (Arch. Pharm. 5, 266. 1836.) legt dem Niederschlage die Formel $\mathrm{N}_{2} \mathbf{H}_{8}, \mathrm{C}_{2} \mathrm{O}_{3}+3 \mathrm{Hg}_{2} \mathrm{O}$ bei; mit dem Resultate seiner Analyse ist aher eine Formel mit $4 \mathrm{Hg}_{2} \mathrm{O}$ ebeusogut vereinbas: Bei directer Bestimmung des Ammoniaks, sowie des Quecksilbers und Be. rechnung desselben als oxalsaures Ammoniak und Quecksilberoxydul, fand er nämlich respective 6,41\% und 90,13\% (nach den Atomzahlen jener Zeit 2,06\% Ammoniak und 86,7\% Quecksilber entsprechend); das Verhältniss zwischen diesen Zahlen ist aber $=\mathrm{N}_{2} \mathrm{H}_{6} \mathrm{C}_{2} \mathrm{O}_{3}: 3,6 \mathrm{Hg}_{2} \mathrm{O}$. Die fehlenden $3,46{ }^{\circ} i_{0}$ sieht er für Verlust an. Unter Hinweis auf $K$ ane's Untersuchung über den Ammoniakniederschlag des Quecksilberchlorürs, bemerkt Berzelius (îrsberättelse 1837 S. 167), dass dieser und mehrere von Harff untersuchte Niederschläge wahrseheinlich Amidverbindungen sind. Dass die Formel $\mathrm{Harff}$ 's daselbst mit $4 \mathrm{Hg}_{.} \mathrm{O}$ wieder gegeben ist, mag vielleicht auf einem Druckfehler beruhen, doch enthalten auch die umgeschriebenen Formeln $8 \mathrm{Hg}$. Souchay und Lenssen (Ann. Chem. 103, 311) geben an, dass die Zusammensetzung veränderlich ist und u. a. davon abhünt, wie viel Ammoniak zugesetzt wird. Sie theilen jedoch nur die Resultate einer Analyse mit, wobei gefunden wurde: $92,19^{\circ} \%$ Quecksilberoxydul, 0,63\% A mmoniak, 4,22\% Oxalsăure und 2,96\% Wasser. Der Ammoniakgehalt beträgt hier nur ein Drittel von dem, was zur Sättigung der Oxalsäure nöthig ist. 
oxydul (wegen der leichten Zersetzung wurde dies nur in ausgewaschenem Zustande benutzt, es konnte deswegen auch keine bestimmte Menge desselben in Arbeit genommen werden) mit Ammoniak zersetzte, den Niederschlag abfiltrirte und, nachdem er ausgewaschen war, mit Schwefelwasserstoff zersetzte. Die Oxalsäure wurcle jetzt in Filtrate sowohl von dem Ammoniakniederschlage als von dem Quecksilbersulfid bestimmt. Das ammoniakalische Filtrat gab, auf ein kleines Volumen eingedunstet, mit Essigsäure angesäuert und mit Calciumchlorid gefällt, einen Niederschlag von oxalsaurem Kalk, der nach starkem Glühen 0,482 Grm. Calciumoxyd hinterliess, und die schwefelwasserstoffhaltige Flüssigkeit. die eingedunstet, mit Ammoniak gesättigt und mit Essigsäure angesäuert wurde, gab auf ähnliche Weise $0,160 \mathrm{Grm}$. CaO. Bei einem zweiten ähnlichen Versuch, für welchen das Quecksilberoxalat durch Fällung mit neutralem Kaliumoxalat dargestellt wurde, erhielt ich auf dieselbe Weise aus den beiden Filtraten resp. 0,219 Grm. und $0,076 \mathrm{Grm}$. Calciumoxyd. Diese Versuche zeigen, dass das erste Filtrat dreimal soviel Kalk fällt, also dreimal soviel Oxalsäure enthält als das zweite, und es geht daraus hervor, dass der Ammoniakniederschlag aus $4\left(\mathrm{Hg}_{2} \mathrm{O}, \mathrm{C}_{2} \mathrm{O}_{3}\right)$ dadurch entsteht, dass $\mathrm{3C}_{2} \mathrm{O}_{3}$ an $\mathrm{A}$ mmoniak gebunden werden, $1 \mathrm{C}_{2} \mathrm{O}_{3}$ dagegen im Niederschlage bleibt. Dieser enthält also $8 \mathrm{Hg}$ auf $\mathrm{C}_{2} \mathrm{O}_{3}$.

Nach dem so gefundenen Verhältnisse zwischen den drei Substanzen, $\mathrm{C}_{2} \mathrm{O}_{3}: \mathrm{N}_{2} \mathrm{H}_{4}: 8 \mathrm{Hg}$, muss der Niederschla g sofern er die Hälfte des Quecksilbers in freiem Zustande enthält und sich übrigens den anderen oben besprochenen Niederschlägen anschliesst, also neben $4 \mathrm{Hg}$ die Verbindung $3 \mathrm{HgO}, \mathrm{C}_{2} \mathrm{O}_{3}, \mathrm{HgN}_{2} \mathrm{H}_{4}$ enthalten. Dies ist aber nach $\mathrm{Millon}^{1}$ ) eben die Zusammensetzung des Ammoniakniederschlages des oxalsauren Quecksilberoxyds. Da diese Verbindung nach ihm wasserfrei ist, muss der schwarze Ammoniakniederschlag also $91,3 \%$ Quecksilber, davon die Hälfte oder $45,65 \%$ in freiem Zustande, enthalten. Dass die oben angegebenen Analysen

1) Ann. Chim. (1846) 18, 410. Nach Harff (a. a. O. S. 229) sollte die Zusammensetzung $\mathrm{N}_{2} \mathrm{H}_{6} \mathrm{C}_{2} \mathrm{O}_{3}+3 \mathrm{HgO}$ sein. Die Formel fordert $79,6 \%$ Quecksilber (die Analyse gab ihm nur 76,9\%; er hat auch hier $4,17 \%$ Verlust), diejenige ron Millon dagegen $84,03 \%$. 
(S. 2:6-227 Anm.) etwas weniger Quecksilber gegeben haben, kamn u. a. vielleicht davon herrübren, dass das Ausgangsmaterial etwas Quecksilberoxyd enthielt.

Der Luft auf dieselbe Weise, wie die vorhergehenden Niederschläge, ausgesetzt, wechselt auch dieser nach und nach die Farbe und wird hell. Derselbe wird jedoch nur dann ganz weiss, wenn er ganz ausserordentlich duinn ausgebreitet ist; auf gewöhnliche Weise wird er bei $100^{\circ}$ hellgelb und bei Zimmertemperatur hell bräunlichgelb, weshalb der Gewichtsverlust dann auch nicht die oben angegebene Grösse von $4 \tilde{5}, 6 \tilde{j}^{\prime} \%_{0}$ erreicht. Nach dem Liegen des Niederschlages bei gewöhnlicher Temperatur hatte er in zwei Monaten $37 \%$ und nach 3 Tagen bei $100^{\circ} 40^{\circ}$ an Gewicht verloren. Wie es demnach zu erwarten war, hinterliessen auch die Rückstände, als sie mit Salzsäure behandelt wurden, etwas Quecksilberchlorür. Der Unterschied zwischen der gefundenen und der berechneten Zahl ist also, besonders bei gewöhnlicher Temperatur, hier bedeutend grösser als bei den oben besprochenen Niederschlägen; es würde wohl sogar Bedenken gegen die angeführte Deutung hervorrufen können, wenn nicht eben die Erfahrungen, die wir bei jenen Niederschlägen gemacht haben (vergl. besonders S. $214 \mathrm{ff}$.), eine solche Annahme stützten. Von diesem Gesichtspunkte aus kann kaum bezweifelt werden, dass die von mir gegebene Deutung die richtige ist, und dass der Unterschied lediglich darauf beruht, dass bei einem Niederschlage etwas mehr Quecksilber in die gebundene Form übergeht, als bei einem anderen.

Aus den oben mitgetheilten Untersuchungen über die schwarzgrauen bis schwarzen Niederschläge, welche durch Einwirkung von überschüssigem Ammoniak auf Quecksilberoxydulsalze entstehen, ergeben sich folgende Hauptresultate.

1. Die Ammoniakniederschläge der Quecksilberoxydulverbindungen geben bei Luftzutritt und unter Umständen, wo keine chemische Zersetzung derselben anzunehmen ist, gegen die Hälfte des enthaltenen Quecksilbers in freiem und gasförmigem Zustande $\mathrm{ab}$; dabei verlieren sie ihre dunkle Farbe.

2. Sie enthalten ursprünglich gleichviel freies und gebun- 
denes Quecksilber (S. 208 und 214), beim Liegen geht aber ein Theil des ersteren in die gebundene Form über. (S. 223.)

3. Die weissen oder hellen Verbindungen, die, nachdem das freie Quecksilber verdunstet ist, zurückbleiben, stimmen mit den Ammoniakniederschlägen der Quecksilberoxydverbindungen überein.

4. Die dunklen Niederschläge sind also nicht, wie bisher allgemein angenommen, Mercuroammoniumverbindungen und enthalten auch nicht solche, sondern sie sind Gemische von Quecksilber und Mercuriammoniumverbindungen. Die $\mathrm{Zu}$ sammensetzung der einzelnen Niederschläge wird durch folgende Formeln ausgedrückt.

$$
\begin{aligned}
& \text { Niederschlag des Nitrates: } 3 \mathrm{Hg}+\mathrm{HgN}_{2} \mathrm{H}_{6} \cdot 2 \mathrm{HgO} \cdot \mathrm{N}_{2} \mathrm{O}_{3} \text { oder } \\
& 3 \mathrm{Hg}+2\left(\mathrm{HgH}_{2} \mathrm{~N} \cdot \mathrm{NO}_{3}\right) \cdot \mathrm{HgO} \text {. } \\
& \text { " } \quad \text { Sulfates: } 4 \mathrm{Hg}+\mathrm{HgN}_{2} \mathrm{H}_{4} \cdot 3 \mathrm{HgO} \cdot \mathrm{SO}_{3} \text { oder } \\
& 4 \mathrm{Hg}+\left(\mathrm{HgH}_{2} \mathrm{~N}\right)_{2} \mathrm{SO}_{4} \cdot 2 \mathrm{HgO} \text {. } \\
& \text { " Chlorürs: } \mathrm{Hg}+\mathrm{HgH}_{2} \mathrm{NCl} \text {. } \\
& \text { " } \quad \text { Oxalates: } 4 \mathrm{Hg}+\mathrm{HgN}_{2} \mathrm{H}_{4} \cdot 3 \mathrm{HgO} \cdot \mathrm{C}_{2} \mathrm{O}_{3} \text { oder } \\
& 4 \mathrm{Hg}+\left(\mathrm{HgH}_{2} \mathrm{~N}_{2} \mathrm{C}_{2} \mathrm{O}_{4} \cdot 2 \mathrm{HgO}\right. \text {. }
\end{aligned}
$$

5. Der schwarze Niederschlag, den Kane durch unvollständige Fällung des Nitrates mit Ammoniak erhielt nnd für eine bestimmte Verbindung ansah, ist ebenfalls ein Gemisch, welches freies Quecksilber enthält, sonst aber von dem unter 4. angeführten verschieden ist. (S. $206 \mathrm{Anm}$.)

6. Das sogenannte Quecksilberchlorür-Ammoniak Rose's, welches aus den wasserfreien Substanzen erhalten wird, stimmt mit dem Niederschlage des Chlorürs überein, nur enthält es zugleich Chlorammonium. 